\title{
The current state of lung transplantation
}

Early attempts at lung transplantation were uniformly unsuccessful. ${ }^{1}$ Many recipients were having assisted ventilation before transplantation and had sepsis with multi-organ failure. The use of high dose corticosteroids as the principal method of providing early immunosuppression severely affected bronchial healing and frequently led to systemic infection.

Acute rejection was difficult to diagnose and often refractory to treatment when recognised. Dehiscence of the airway anastomosis, ${ }^{\prime}$ related to bronchial ischaemia, was almost invariable in short term survivors and seemed an insuperable problem. The technical difficulties have been largely overcome by approaches that have solved the problem of bronchial healing. Immunosuppression with cyclosporin A allows more selective use of corticosteroids in the early postoperative course. Finally, the importance of selection of patients is now recognised and indications for each of the available procedures are being established.

\section{Heart-lung transplantation}

Heart-lung transplantation was introduced for the treatment for pulmonary vascular disease, ${ }^{2}$ and has become a therapeutic option for a wide range of patients, including those with end stage lung disease. ${ }^{3}$ Most recipients still have pulmonary vascular disease, ${ }^{4}$ but the proportion with primary lung disease is increasing and now comprises $40 \%$ of all cases, according to the current International Registry. ${ }^{5}$ Heart-lung transplantation was the first form of lung transplantation to be introduced successfully into clinical practice. A tracheal anastomosis heals much more reliably than a bronchial anastomosis because of the presence of coronary to bronchial collaterals. ${ }^{6}$ More importantly, it has the advantage that all the diseased pulmonary tissue is removed. The most common pulmonary indications for heart-lung transplantation are emphysema (especially $\alpha_{1}$ antitrypsin deficiency), bronchiectasis and cystic fibrosis. Patients with cystic fibrosis represent a large group of potential recipients and initial results of heart-lung transplantation in this group are encouraging.?

Successful heart-lung transplantation depends on rigorous selection of suitable candidates and, though

Address for reprint requests: Mr J Dark, Regional Cardiothoracic Centre, Freeman Hospital, Newcastle upon Tyne NE7 7DN. individual transplant units inevitably have their own criteria, a broad consensus is emerging. The shortage of suitable donors is reflected in the upper age limit of 49 years, and all patients should have respiratory failure unresponsive to conventional medical treatment and a poor quality of life. There should be no appreciable dysfunction of other major organs, particularly the kidneys and liver. This is particularly relevant to patients with cystic fibrosis, who of ten have liver disease. ${ }^{8}$ A previous sternotomy or thoracotomy is not an absolute contraindication but will increase the risk of severe postoperative bleeding from the chest wall. ${ }^{9}$ Extensive pleural thickening visible on the chest radiograph constitutes a similar disadvantage. A pleurectomy carried out for recurrent pneumothoraces substantially increases the risk of transplantation and is a contraindication in most centres.

The current demand for heart-lung transplantation is high and about 200 potential recipients die annually of pulmonary disease in the United Kingdom. ${ }^{3}$ The shortfall in suitable donor organs means that heartlung transplantation cannot be offered on an emergency basis or to moribund patients; in general, patients requiring full time assisted ventilation are not considered suitable.

The overall one year survival worldwide is $60 \%$, ${ }^{5}$ though individual centres report survival rates as high as $71 \%$ and $78 \%{ }^{10}$ The higher figures may reflect the use of transbronchial biopsy to diagnose rejection and strategies to protect against common opportunist organisms. Survival rates in patients with primary lung disease now appear to be similar to those in patients with pulmonary vascular disease.

Rehabilitation in survivors is excellent, with restoration of a normal life style in most and little or no functional restriction. The pattern of breathing at rest, both in the waking state and during sleep, seems to be no different from that of normal individuals." Ventilation during exercise follows the pattern seen after heart transplantation, with a higher minute ventilation and tidal volume for a given oxygen consumption than in normal individuals. ${ }^{12}$

Though recurrence of disease in transplanted lungs remains a concern, there is so far no published evidence to suggest that this has caused clinical problems. Granulomas, however, have been seen in transbronchial lung biopsy specimens in patients undergoing transplantation for sarcoidosis (J Scott, T 
Higenbottam, personal communication); but the characteristic abnormality of the respiratory mucosa in cystic fibrosis (a high bioelectrical mucosal potential difference $^{13}$ ) has not been seen up to two years after heart-lung transplantation. ${ }^{14}$ Patients with $\alpha_{1}$ antitrypsin deficiency will be potential candidates for replacement treatment when this is available, though stopping smoking is probably more important.

\section{Single lung transplantation}

Single lung transplantation offers an alternative approach for patients with chronic fibrotic pulmonary disease, particularly cryptogenic fibrosing alveolitis. Such patients are particularly suitable for this form of transplantation as the transplanted lung, more compliant and with a lower pulmonary vascular resistance, is preferentially ventilated and perfused after surgery. ${ }^{15}$ Suitable patients are hypoxaemic at rest, become further desaturated with minimal exercise, and are unresponsive to conventional medical treatment. Previous surgery or some obliteration of the pleural space is not a contraindication. Not only can the less affected side be chosen but cardiopulmonary bypass is rarely necessary, so the risk of haemorrhage is less. Because the perioperative course is usually smoother than with heart-lung transplantation (and slightly more donor organs are available) patients up to the age of 60 can be accepted. The other selection criteria are the same as for recipients of heartlung transplants.

The integrity and revascularistion ${ }^{16}$ of the bronchial suture line is ensured by wrapping the anastomosis in a pedicle of greater omentum. It is, however, important to wean patients on to as low a dose of corticosteroids as possible before surgery to aid healing at this site. Other immunosuppressive treatment, such as azathioprine or cyclophosphamide, has been shown not to affect healing. ${ }^{17}$ Medium term results are available from only one substantial series, from the Toronto group $^{18}$; but a one year survival rate of $60 \%$ is to be expected. This will almost certainly improve to levels enjoyed by recipients of heart-lung transplants as experience increases.

Functional results are excellent, with restoration of gas exchange and an exercise capacity that allows a normal life style. ${ }^{19}$ Single lung transplantation has manifest advantages, particularly for the patient with previous surgery, and it makes economical use of donor organs. The heart and both lungs from one donor can be used, permitting three recipients to benefit. $^{20}$ Despite these advantages, application is largely restricted at present to patients with end stage pulmonary fibrosis. Early experience of single lung transplantation in patients with emphysema was unsatisfactory, the transplanted lung becoming com-

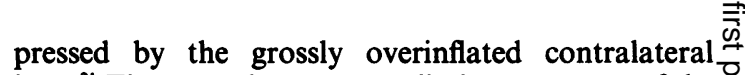
lung. ${ }^{21}$ There are, however, preliminary reports of the $\frac{}{0}$ use of single lung transplantation in this setting more $\frac{}{\bar{N}}$ recently, with satisfactory early results. ${ }^{22}$ Single lung $\vec{\Phi}_{\overparen{D}}$ transplantation is unlikely ever to be applied to $\varrho$ patients with chronic lung infection, such as those with is cystic fibrosis, because of the inevitable spread of $\overrightarrow{0}$ infection from the contralateral lung in an immunosuppressed patient.

\section{The future}

Most of the unsolved problems in lung transplantation are common to both types of transplant. Lung $\underset{0}{0}$ preservation is in its infancy. Various methods have $\circ$ been reported, including flushing of the pulmonary bed with cold blood ${ }^{23}$ or crystalloid ${ }^{24}$ or core cooling of $\overrightarrow{C S}$ the donor with cardiopulmonary bypass. ${ }^{25}$ These allow $\frac{\mathbb{8}}{8}$ an ischaemic time of four to six hours. All result in $\mathbb{\mathbb { D }}$ some initial dysfunction, which usually recovers over $\frac{3}{0}$ the first few days. Future research will be directed $\stackrel{\Phi}{-}$ towards reducing this lung injury, which shares many $\vec{\bullet}$ of the characteristics of the adult respiratory distress $\infty_{0}^{\infty}$ syndrome.

Opportunist infection is the greatest cause of mortality and morbidity in the first few months after transplantation. The particular importance of primary cytomegalovirus infection in the transplanted lung is $\frac{\circ}{\varnothing}$ now recognised..$^{26} \mathrm{It}$ is largely avoided by appropriate $\stackrel{\varnothing}{\square}$ matching of donor to recipient or, more expensively, $\overrightarrow{\vec{O}}$ by use of prophylactic cytomegalovirus hyper- 3 immunoglobulin in non-matched patients. If infection does occur, the newer antiviral agent DHPG (gancyclovir) is of value. ${ }^{26}$ Acute lung rejection may be diagnosed histologically from transbronchial lung $\frac{0}{N}$ biopsy specimens, ${ }^{27}$ though the rejection process is $x$ clearly patchy and may lead to sampling error. The $\frac{0}{3}$ combination of transbronchial lung biopsy and bronchoalveolar lavage permits diagnosis of radiological infiltrates or a fall in pulmonary function in most patients after transplantation. Open lung biopsy is rarely required. The importance of serial $\rightarrow$ pulmonary function testing in the detection of rejection and infection is recognised by most groups. N Pulmonary rejection may occur in the absence of cardiac rejection, ${ }^{28}$ and endomyocardial biopsy is of ${ }_{N}^{N}$ no value in diagnosing lung rejection. ${ }^{29}$

The most common cause of late morbidity and mortality is progressive airways obstruction, with ace histological picture of obliterative bronchiolitis. ${ }^{30}$ This $\mathbb{\Phi}$ has been described in up to $30 \%$ of long term? survivors ${ }^{31}$ and follows both heart-lung and single lung $\underset{T}{0}$ transplantation. It is probably a manifestation of $\frac{\vec{C}}{\vec{D}}$ chronic rejection ${ }^{32}$ and would seem to be more $\stackrel{\Phi}{\odot}$ common in patients who have had repeated early $\underset{\mathbb{Q}}{\varrho}$ rejection episodes. It may also be triggered by viralo 
infection. ${ }^{33}$ In the early stages it may be reversed by augmented immunosuppression. ${ }^{34}$

Future expansion of pulmonary transplantation will be limited by the number of donors and economical use of organs is of great importance. We may expect to see expansion of the role of single lung transplantation. Patients with respiratory disease who have adequately preserved cardiac function can participate in the so called "domino" procedure: when they receive a new heart and lungs their own heart can be used for a recipient of a heart transplant. The alternative approach of double lung transplant, preserving the recipient's own heart (and using the heart from the donor for another recipient ${ }^{35}$ achieves the same economy of donor organs, but it has met with problems of tracheal dehiscence and has now been largely abandoned in its original form (GA Patterson, personal communication).

Lung transplantation is at the same stage as cardiac transplantation in the early 1980s. The prospects for the next few years are very exciting.

\section{J DARK \\ P A CORRIS \\ Regional Cardiothoracic Centre Freeman Hospital Newcastle upon Tyne}

\section{References}

1 Wildevuuer CRH, Benfield JR. A review of 23 lung transplantations by 20 surgeons. Ann Thorac Surg 1972;9:489-515.

2 Reitz BA, Wallwork J. Hunt SA, et al. Heart lung transplantation: a successful therapy for patients with pulmonary vascular disease. $N$ Engl $J$ Med 1982;306:557-63.

3 Penketh A, Higenbottam T, Hakim M, Wallwork J. Heart and lung transplantation in patients with endstage lung disease. Br Med J 1987;295:311-4.

4 Reitz BA. Heart lung transplantation. Chest 1988;93:451-2.

5 Kaye MP. The registry of the International Society for Heart Transplantation. Sixth official report, 1989. $J$ Heart Transplant (in press).

6 Sadeghi A, Guthaner DF, Wexler L, et al. Healing and revascularisation of the tracheal anastomosis following heart lung transplantation. Surg Forum 1982;33:236-8.

7 Scott J, Hutter J, Stewart S, et al. Heart lung transplantation for cystic fibrosis. Lancet 1988;ii:192-4.

8 Webster R, Williams H. Hepatic cirrhosis associated with fibrocystic disease of the pancreas. Arch Dis Child 1953;28:343-50.

9 Griffiths BP, Hardesty RL, Trento A, et al. Heart-lung transplantation: lessons learned and future hopes. Ann Thorac Surg 1987;43:6-16.

10 Hutter J, Despins P, Higenbottam T, Stewart S, Wallwork J. Heart-lung transplantation: better use of resources. Am J Med 1988;85:4-11.

11 Shea SA, Horner RL, Banner NR, et al. The effect of human heart lung transplantation upon breathing at rest and during sleep. Respir Physiol 1988;72:131-50.

12 Sciurha FC, Owens GR, Sanders MH, et al. Evidence of an altered pattern of breathing during exercise in recipients of heart lung transplants. $N$ Engl $J$ Med 1988;319:1186-92.

13 Knowles M, Gatzy J, Bouchet R. Increased bioelectrical potential difference across respiratory epithelium in cystic fibrosis. N Engl J Med 1981;305:1489-95.

14 Wood AM, Jackson M, Miller M, Higenbottam T, Wallwork J. Transepithelial potential difference in the transplanted lung of patients with and without cystic fibrosis [abstract]. Am Rev Respir Dis 1988;137:A220.

15 McLeod AT, Stone TN, Hawkins T, Dark JH, Corris PA. Ventilation/perfusion relationships after single lung transplantation for pulmonary fibrosis [abstract]. Am Rev Respir Dis 1989;139:A265.

16 Dubois P, Choiniere L, Cooper JD. Bronchial omentopexy in canine lung allotransplantation. $A n n$ Thorac Surg 1984;38:211.

17 Goldberg M, Lima O, Morgan E, et al. A comparison between cyclosporin $\mathrm{A}$ and methylprednisolone plus azathioprine on bronchial healing following canine lung autotransplantation. $J$ Thorac Cardiovasc Surg 1983;85:821-6.

18 Toronto Lung Transplant Group. Experience with single lung transplantation for pulmonary fibrosis. JAMA 1988;259:2258-62.

19 McGregor CGA, Conacher I, Hilton CJ, Dark JH, Corris PA. Early results after single lung transplantation for pulmonary fibrosis. $J$ Thorac Cardiovasc Surg (in press).

20 Brodman RF, Veith FJ, Goldsmith J, et al. Multiple organ procurement from one donor. Heart Transplant 1985;4:254-7.

21 Stevens PM, Johnson PC, Bell RL, Beal AC, Jenkins DE. Regional ventilation and perfusion after lung transplantation in patients with emphysema. $N$ Engl J Med 1970;282:245-9.

22 Andreassian B. Panlobular emphysema in the terminal stage: unilateral pulmonary graft [letter]. Presse Méd 1988;17:822-3.

23 Wallwork J, Jones K, Cavarrochi N, Hakim M, Higenbottam T. Distant procurement of organs for clinical heart lung transplantation using a single flush technique. Transplantation 1987;44:554-8.

24 Kirk AJB, Corris PA, Conacher I, Hilton CJ, Dark JH. Clinical results with a flush perfusion method of lung preservation [abstract]. J Heart Transplant 1989;8:92.

25 Yacoub MH, Khaghani A, Banner N. Distal organ procurement for heart lung transplantation [abstract]. In: Proceedings of the 12th international congress of the World Transplantation Society, Sydney, Australia. August 1988:206.

26 Penketh ARL, Higenbottam TW, Hutter J. Clinical experience in the management of pulmonary opportunist infection and rejection in recipients of heart lung transplants. Thorax 1988;43:762-9.

27 Higenbottam T, Stuart S, Penketh A, Wallwork J. Transbronchial lung biopsy for the diagnosis of rejection in heart lung transplant recipients. Transplantation 1988;46:532-9. 
28 McGregor CGA, Baldwin JC, Jamieson SE, et al. Isolated pulmonary rejection after combined heart lung transplantation. $J$ Thorac Cardiovasc Surg 1985;90:623-30.

29 Higenbottam T, Hutter JA, Stuart S, Wallwork J. Transbronchial biopsy has eliminated the need for endomyocardial biopsy in heart lung recipients. J Heart Transplant 1988;7:435-9.

30 Burke CM, Theodore J, Baldwin JC, et al. 28 cases of human heart-lung transplantation. Lancet 1986;i:5179.

31 Burke CM, Theodore J, Hawkins KD, et al. Posttransplant obliterative bronchiolotis and other late sequelae in human heart lung transplantation. Chest 1984;88:824-9.
32 Tazelaar HD, Prop J, Nieuwenhuis P, et al. Airway pathology in the transplanted rat lung. Transplantation $1988 ; 45: 864-9$

33 Burke CM, Glanville AR, Macoviak JA, et al. The spectrum of cytomegalovirus infection following human heart lung transplantation. J Heart Transplant 1986;5:267-71.

34 Glanville AR, Baldwin JC, Burke CM, Theodore J, Robin ED. Obliterative bronchiolitis after heart lung transplantation: apparent arrest by augmented immunosuppression. Ann Intern Med 1987;107:300-4.

35 Patterson GA, Cooper JD, Dark JH, et al. Experimental and clinical double lung transplantation. $J$ Thorac Cardiovasc Surg 1988;95:70-5. 